\title{
Friendly Alien: Object and Interface
}

by Lev Manovich, The Visual Arts Department, University of California, San Diego

Since 1996, artist Miltos Manetas has done paintings that systematically portray the new essential objects of contemporary life: joysticks, computers, computer game consoles, and computer cables (lots of them). Manetas also paints people who are usually intensely engaged in the activities made possible by consumer electronics devices, such as playing a computer game. But he never shows what games they are playing or what images they are looking at. Instead, he focuses on the humancomputer interface: hands clutching a joystick, a body stretched across the floor in the intense concentration or, alternatively, relaxing besides a laptop, a computer console, or a TV.

Manetas's paintings of the 1990s reflected the then popular views of the computer as an unfamiliar and foreign presence, even an alien; computer work as immersion and withdrawal from the physical surroundings; the laptop or the game console "sucking in" the user away from the immediate space (similar to the vision of TV in Cronenberg's 1982 Videodrome). The orgy of electronic cables in these paintings, which seem to grow and multiply, bring references to the cyborg and science fiction movies such as Alien and Matrix.

In contrast, his latest paintings, such as Nikescape (2005), represent technology as being completely integrated and fused with the lived environment: items of fashionable clothing and computer cables become complementary; the atmosphere is decorative and festive. Technology is neither threatening nor some outside force that has been domesticated. Rather, it is playful and playable: it brings a party into the everyday. The sound that accompanies our interaction with the icons, the icons that playfully unfold into windows in MAC OS $X$, colorful desktop backgrounds, shiny reflective surfaces, and anthropomorphic shapes - all this makes computers and consumer electronics devices stand out from the everyday grayness. Technology is a pet that surprises us, sometimes disobeying and even annoying us - but it is always animated, always entertaining, always fun and almost fashionable.

My visit to the famous Collette store in Paris the same day in 0ctober 2005 that I saw Nikescape in Manetas's studio only confirmed this new identity of consumer technology today. Collette is a legendary store which in the middle of the 1990s introduced a new concept that today has become an accepted genre: store as collection of the most interesting design objects currently being created around the world, with an obligatory cool cafe' and changing art exhibitions.

Situated across from the entrance was the new display positioned right in the center of the store. It housed the latest cell phones, PDAs and a portable Sony Playstation. These "techno-jewels" came to dominate the store, taking the space away from albums, perfumes, clothes, and various design objects that were all now occupying the perimeter. But, just as in Manetas's new paintings, the techno-objects in the case did not look dominating, threatening, or alien. They seemed to acquire the same status as perfume, photography books, clothes, and other items in the store. Put differently, they were no longer "technology". Instead, they became simply "objects" and as such they now had the same right as other objects that we use daily to be beautiful and elegant, to have interesting shapes and textures, to reflect who we use and at the same time allow us to reinvent ourselves. In short, they now belonged to the world of design and fashion rather than engineering. 


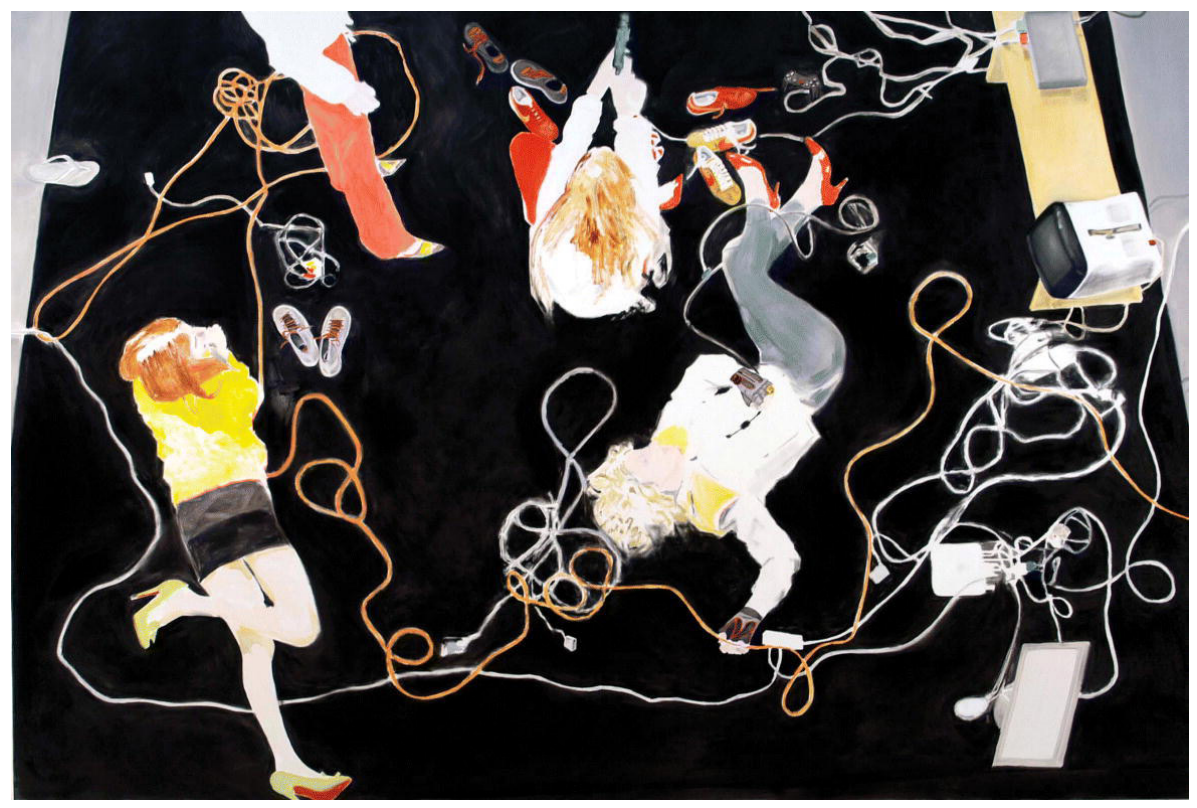

Figure 1.

NIKESCAPE (2005). 200/300 cm.

Collection DAKIS JOANNOU, PARIS.

Yet, as another display in Collette made clear, the integration was far from complete. Sony had just commissioned 10 top fashion designers to design cases for the PSP (Portable Sony Playstation) and they were presented in the store. The cases were disappointing: although they used avariety of materials, patterns, colors, and designs, none of them seemed integrated with PSP design - the refinement and minimal logic of PSP menu screens, the way they slide horizontally, etc. What I saw in each case was two completely different design logics not talking to each other at all.

I feel similar unease at some of the recent attempts to make cell phones more "fashionable" by adding easily recognizable signs of fashion: encrustation, silver textures, "art deco" patterns. The problem is that technoobjects are not ordinary objects. This applies equally to cell phones, PDAs, portable game players, portable music players, portable video players, etc. They all contain interfaces most often a screen for output and input and a few buttons, and sometimes also a trackwheel, or a small built-in keyboard. And behind the screen lives a whole separate world with its logic, aesthetics, and dynamics. And when this electronic screen and the world it presents to us ends (I am talking about the physical boundary of the screen), this creates a visual and psychological feeling of discontinuity. Suddenly we are in a different world - that of non-interactive, "dead" surfaces that enclose the screen. And typically the design of these surfaces does not have much to do with the design of the screen interface. The "fashion" cases for PSP exemplify this situation. All the cases were nice in themselves but the associative worlds they invoked had nothing to do with the world inside a PSP screen.

Let me put these experiences in more general terms. Today the design of forms is becoming intricately linked with the question of interface. First of all, we need to give some visual form to what will appear on the screens of computers, mobile phones, PDAs, car navigation systems, and other devices - as well as to buttons, trackwheels, microphones, and various other input tools. Therefore, human computer interfaces that involve a set of visual conventions such as folders, icons, and menus (i.e. a graphical user interface), audio conventions (as in the voice recognition interface), and particular material articulations (such as the shape, color, material, and texture of a mobile phone) represent the whole new category of forms that need to be designed today. Even more importantly, as computation becomes incorporated in our lived environment (the trend that is described by such terms as "ubiquitous computing", "pervasive computing", "ambient intelligence", “context-aware environments", “smart objects") the interfaces slowly leave the realm in which they lived safely for a few decades - that is, stand-alone computers and electronics devices and start appearing in all kinds of objects and on all kinds of surfaces, be it interior walls, furniture, benches, bags, clothing, and so on. Consequently, the forms of all these objects that previously lived "outside information" now have to address the likely presence of interfaces somewhere on them. 
This does not mean that from now on "form follows interface". Rather, a physical form and an interface have to learn how to accommodate each other. Beyond the traditional requirements that the material forms have to satisfy - a chair has to be comfortable for sitting on, for example - their design is now being shaped by new requirements. For instance, at least so far,we are used to interacting with text that is presented on a flat and rectangular surface, and therefore if a screen is to be incorporated somewhere in the object, part of it needs to be reasonably flat. This is easy to do if an object is a table but not as easy if it is a piece of clothing or Gerry's Disney Hall in Los Angeles that is specifically designed not to have a single flat area. (Of course, as new technologies such as Rapid Manufacturing may soon enable the easy printing of an electronic display on any surface of any object while it is being produced, it is possible that we shall be able to quickly adjust our perceptual habits, so that moving and change-shaping display surfaces will be accepted much more easily than I can imagine. In fact, the computercontrolled graphic projections on the body of dancers, as in Apparition by Klaus Obermair or in Interactive Opera Stage system by Art+Com, already show the aesthetic potential of displaying information over a changing, nonflat, nonrectangular form, i.e. a human body.)

In short, today the interface and the material object that supports it still seem to come from different worlds. The interface is a "friendly alien" but it is still the alien. The task of rethinking both interface and objects together so that they can be fused into a new unity is not an easy one and it will require much work and imagination before aesthetically satisfying solutions can be found.

In conclusion, let me describe my visit to a show of student projects from the Department of Industrial Design at Eindhoven Technical University in the Netherlands, which I saw during Dutch Design Week in the fall of 2005. The department is only three years old, so instead of designing traditional objects students are working on "smart objects". Every project in the show starts with an everyday familiar object and adds some "magical" functions to it via electronics and computers. This means that I see more examples of solid objects and media/interface surfaces coming together. In one project, a canopy placed diagonally over a child's bed in a hospital becomes an electronic canvas. By tracking the position of a special pen that does not need to touch the drawing surface, the canvas allows the child to draw on it without having to move from the bed. In another project, a special mirror allows one person to leave a message for somebody else - for instance, a different member of a household. A rectangular block containing a camera is built into a mirror frame. You take the block out, record a video message and place the block back into the frame. After you do this, the video is automatically "loaded" into the magical mirror, and a small picture appears somewhere on the mirror's surface. When you click on the picture it plays a video message. Yet another project adds magical interactivity to a vertical plastic column. The lights inside the column turn it into an ambient light source. The column is covered with a special interface: a net. Depending on how you touch the net, the position, quality, and tint of the light changes. How exactly the light will change is not directly predictable, and this is what makes the interaction with the light column fun. There is real magic in all these "smart objects": we see familiar, normally passive objects literally coming to life and responding to our interactions with them.

Together, these three projects show us different ways in which an object, an interface, and a display can be put together. The first two projects rely on already familiar behaviors - drawing with a pen or making a recording with a video camera. The last one calls for the user to develop a new vocabulary of movements and gestures to which the light will respond. And the ways in which a "smart object" talks back to us are also different: a canvas canopy shows a drawing, a mirror plays a video, and a light glows in different ways. In short, the surface of an object can become both an output and input medium, bringing together the physical and the screen-like form and information - in surprising ways.

\section{CORRESPONDENCE}

Lev Manovich,

The Visual Arts Department, University of California, San Diego, 9500 Gilman Dr.

La Jolla CA, 92093-0327

Published online 2006-11-15

ISSN 1749-3463 print/ ISSN 1749-3471

DOI: $10.1080 / 17493460600612307$

(C) 2007 Artifact 